\title{
Chocolate cyst became ovarian abscess following IVF: a serious surgical emergency
}

\author{
Poonam Yadav, Namita Agrawal*, Sarah Zaidi, S. Fayyaz
}

Department of Obstetrics and Gynecology, Santokba Durlabhji Memorial Hospital, Jaipur, Rajasthan, India

Received: 11 March 2018

Accepted: 05 April 2018

\section{*Correspondence:}

Dr. Namita Agrawal,

E-mail: namitaagarwalsms@gmail.com

Copyright: (C) the author(s), publisher and licensee Medip Academy. This is an open-access article distributed under the terms of the Creative Commons Attribution Non-Commercial License, which permits unrestricted non-commercial use, distribution, and reproduction in any medium, provided the original work is properly cited.

\begin{abstract}
We are reporting a rare case of ovarian abscess in an endometrioma following ultrasound guided oocyte retrieval during in vitro fertilization technique. Ovarian abscess within an endometrioma is a rare gynaecological problem. We are presenting a case of a giant abscess formation in an endometrioma following in vitro fertilization in a 36-year-old woman in view of secondary infertility. She presented with high grade fever with chills and rigor for more than 2 months associated with pain in abdomen with a progressively increasing lower abdominal mass. Patient was treated at a tertiary care hospital with multidisciplinary approach. Laparotomy was performed, and two litres of the foulsmelling pus was drained, followed by bilateral salpingooophorectomy. Uterus was left in situ to preserve her future fertility potential. Histology of the specimen confirmed endometriotic nature of the cyst. Pus on culture sensitivity was sterile. Patient had an uneventful recovery and was discharged on the $7^{\text {th }}$ post-operative day. In our case endometrioma presented as failure of in vitro fertilization technique followed by a medical illness. This case highlights that endometrioma became not only a cause of failure of in vitro fertilization technique but also presented as a medical illness and should be dealt as one.
\end{abstract}

Keywords: Bilateral salpingoophorectomy, Endometrioma, In vitro fertilization technique, Ovarian abscess, Secondary infertility, Ultrasound guided oocyte retrieval

\section{INTRODUCTION}

Endometriosis is ectopic growth of endometrial glands and stroma. It occurs in commonly in the pelvis and affects most commonly ovary followed by pouch of Douglas. In the ovary, endometriosis is called as endometrioma or chocolate cyst. ${ }^{1}$ Endometriosis is commonly occurred in the reproductive age group distributed from 14 years to 49 years of age. Patients of endometriosis commonly remain asymptomatic but symptomatic patient's presents in a classical triad dysmenorrhoea, dyspareunia and infertility. ${ }^{2}$ Endometriosis is commonly diagnosed with the help of laparoscopy. Management of the endometriosis is medically and surgically, depends on woman specific complains, symptom severity, location of endometriotic lesion, goal of treatment and desire to conserve future fertility. ${ }^{3}$ If view of preserving fertility surgically management of endometriosis is preferred. However, endometriosis is hard to treat due to high reoccurrence after the surgical clearance. Operative laparoscopy is beneficial up to some extent in grade III/IV endometriosis but invitro fertilization (IVF) is the preferred modality rather than reoperation in case of unsuccessful surgery. ${ }^{4}$ But treatment is necessary because endometriosis causes socially, psychological and physically impairment. IVF commonly complicates as infection, haemorrhage, sepsis, ovarian abscess. Success rate is nearly $30 \% .^{5}$ In the present case we are discussing a disastrous life 
threatening surgical emergency of chocolate cyst in a secondary infertile woman underwent IVF.

\section{CASE REPORT}

A 36-year-old female known case of secondary infertility presented with high grade fever with chills and rigour for two months. Fever was progressively increasing in intensity and patient was not getting relief even after medical management.

She had a past history of bilateral endometriomas diagnosed by both trans-vaginal and transabdominal ultrasound. She underwent laparoscopic removal of same for twice first in December 2010 second in November 2011. In view of management of secondary infertility, she underwent hysterolaparoscopy in December 2016; which was reported as a normal study and patient was advised for in vitro fertilization.

She had her last menstrual period on 7th February 2017. The oocyte retrieval was performed on 19th February 2017 following ovulation induction followed by embryo transfer on $22^{\text {nd }}$ February 2017. But results of IVF were declared as failed on $15^{\text {th }}$ March 2017. Following this patient developed high grade fever with chills and rigour from 20 $0^{\text {th }}$ March 2017.

So, patient visited at our hospital in the emergency department on $14^{\text {th }}$ May 2017. On examination, her body temperature was $1010 \mathrm{~F}$, pulse was 120 beats per minute, and blood pressure was $100 / 70 \mathrm{~mm}$ of $\mathrm{Hg}$. She appeared pale and clammy. On inspection umbilicus was shifted upwards, abdomen was distended below the umbilicus. On palpation, a palpable firm mass was felt in the lower abdomen arising from pelvis measuring approximately 20 weeks size of pregnant uterus. Her hemoglobin, WBC and CA-125 were $8.7 \mathrm{~g} / \mathrm{dl}, 18,300 / \mathrm{mm} 3$ and 34.5 respectively. Her chest X-ray showed clear bilateral lung fields. MRI pelvis showed cystic lesions in bilateral adnexal region measuring approximately $84 \times 40 \times 112 \mathrm{~mm}$ on right side and $93 \times 96 \times 102 \mathrm{~mm}$ on left side (Figure 1).

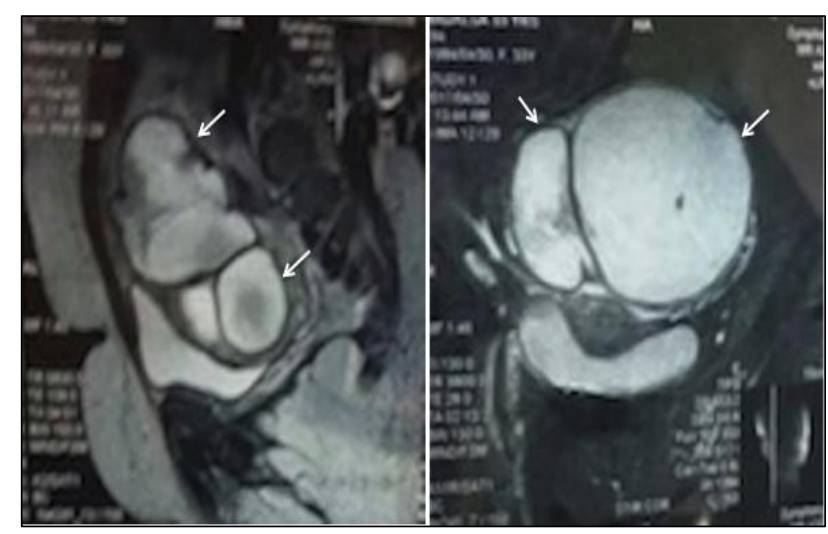

Figure 1: T2 weighted Sagittal and coronal MRI images of the pelvis show large cystic lesions in bilateral adnexa (arrows).
So, patient was admitted and planned for laparotomy with co-ordination of gastrointestinal surgeon. On laparotomy, a left sided ovarian abscess of approximately $20 \times 20 \mathrm{~cm}$ sized, filled with foul smelling pus $\sim 2$ liter in quantity retrieved. That ovarian abscess was adherent to bowel loops on all around and on the posterior surface of uterus. Similarly, on right side right ovary was also found to be enlarged $\sim 5 \times 5 \mathrm{~cm}$ sized and adherent on all around with bowel loops and also filled with foul smelling pus. Bilateral salpingoophorectomy (after informed and written consent) with separation of bowel loops by blunt and sharp dissection was performed. Total abdominal hysterectomy was not done as patient wanted to retain her uterus for preservation of fertility with the help of ovum donor.

The whole specimen saved and sent for histopathological examination which revealed endometriotic cyst walls, and pus culture was negative for both aerobic and anaerobic organism. Abdomen closed after air leak test by gastrointestinal surgeon.

Patient was kept nil by mouth for 48 hours followed by 48 hours on liquid diet followed by semisolid diet for next 3 days then discharged on $7^{\text {th }}$ postoperative day in satisfactory condition. In the post-operative period patient was absolutely afebrile. She was followed up after an interval of one week and she was fine.

\section{DISCUSSION}

Endometriosis is called as missed disease because the average time between onset of pain and diagnosis is nearly $8-12$ years. ${ }^{6}$ Besides pelvic pain endometriosis is also responsible for dyspareunia and infertility. Senapati et al described that IVF is better option to achieve fecundity rather than reoperation in case of infertility with endometriosis. ${ }^{4}$ But surgical correction of chocolate cyst is hard core requirement even prior IVF, otherwise it can not only be responsible for failure of IVF but also may cause terrifying life threatening surgical emergency in the form of ovarian abscess and its rupture. There are so many complications in trans-vaginal oocyte retrieval eg. Injury to blood vessels and haemoperitoneum, trauma to the pelvic organ infection, exacerbation of pelvic inflammatory disease, abscess of endometriomas etc. ${ }^{5}$

A few possible explanations are about formation of an ovarian abscess in chocolate cyst. Firstly, blood acts as favourable culture media for various pathogens specially altered menstrual blood, which is found to be collected in the cystic ovarian spaces. Secondly, epithelium of the chocolate cyst is comparatively weaker than the normal ovarian epithelium, so it becomes susceptible to bacterial invasion. Thirdly, there may be altered immune environment within the ectopic endometrial glands and stroma. ${ }^{7}$ Kubota et al found that the incidence of tuboovarian abscess formation is 11.5 time higher in patient with endometrioma as compared patient without endometrioma $(\mathrm{p}=0.0001){ }^{8}$ 
Treatment of ovarian abscess varies depending on the clinical situation. Giant ovarian abscess can be life threatening if they get ruptured so requires prompt intervention. Definitive management of large ovarian abscess is surgical excision via laparoscopically or by laparotomy. Sometimes laparoscopic approach may not be possible because of severe pelvic adhesions secondary to the abscess formation. Also, the risk of visceral injury would be higher when significant amount of adhesions is present. In this case, laparotomy was found to be the best option. Therefore, after informed and written consent bilateral salpingoophorectomy done with preservation of uterus in view to achieve conception with the help of oocyte donation in future.

\section{CONCLUSION}

Though endometriosis is not uncommon, responsible for infertility is also very well-known fact but high index of suspicion is required for development of ovarian abscess for a woman presenting with high grade of fever not relieving by any medication, following IVF failure with endometriosis as it may be life threatening or may present as surgical emergency.

Funding: No funding sources Conflict of interest: None declared

Ethical approval: Not required

\section{REFERENCES}

1. Acién P, Velasco I. Endometriosis: A disease that remains enigmatic. ISRN Obstetrics Gynecol. 2013;2013:242149.
2. Shah PR, Adlakha A. Laparoscopic management of moderate: Severe endometriosis. Jf Minimal Access Surgery. 2014;10(1):27-33.

3. Hoffman BL, Schorge JO, Bradshaw KD, Halvorson LM, Schaffer JI, Corton MM. Williams Gynecology. Endometriosis. $3^{\text {rd }}$ edition. United states of America; McGraw-Hill education; 2016;10:230-248.

4. Senapati S, Barnhart K. Managing endometriosis associated infertility. Clin Obst Gynecol. 2011;54(4):720-6.

5. Kelada E, Ghani R. Bilateral ovarian abscesses following transvaginal oocyte retrieval for IVF: a case report and review of literature. J Assisted Reprod Genetics. 2007;24(4):143-5.

6. Moradi M, Parker M, Sneddon A, Lopez V, Ellwood D. Impact of endometriosis on women's lives: a qualitative study. BMC Women's Health. 2014; $14: 123$.

7. Hameed A, Mehta V, Sinha P. A rare case of de novo gigantic ovarian abscess within an endometrioma. Yale J Biol Med. 2010;83(2):73-5.

8. Kubota T, Ishi K, Takeuchi H. A study of tuboovarian and ovarian abscesses, with a focus on cases with endometrioma. J Obstet Gynaecol Res. 1997;23:421-6.

9. Shah, Rameshvari C, Shah JM, Mehta MN. Laparoscopic management of an endometrioma complicated by an ovarian abscess. Int J Reprod Contracept Obstet Gynecol. 2013;2(3):473-4.

Cite this article as: Yadav P, Agrawal N, Zaidi S, Fayyaz S. Chocolate cyst became ovarian abscess following IVF: a serious surgical emergency. Int J Reprod Contracept Obstet Gynecol 2018;7:2052-4. 